\section{International Scientific Journal Theoretical \& Applied Science}

p-ISSN: 2308-4944 (print) e-ISSN: 2409-0085 (online)

Year: $2014 \quad$ Issue: 12 Volume: 20

Published: $30.12 .2014 \quad$ http://www.T-Science.org
Alexandr Nikolayevich Shevtsov candidate of technical sciences, member of Publishers International Linking Association (USA), President of International Academy TAS, deputy director on Science of FITAT, Taraz State University M.Kh. Dulati, Kazakhstan Shev_AlexXXXX@mail.ru

SECTION 5. Innovative technologies in science.

\title{
THE PRIORITIES OF THE DEVELOPMENT OF SCIENTIFIC JOURNAL
}

Abstract: Globalization of science inevitably leads to the emergence and development of new scientific journals are able to meet the changing environment, indexed in a large number of international scientometric databases, and recognized by international agencies and associations. The article describes aspects of the work of the international scientific journal ISJ Theoretical \& Applied Science and the priorities for further development.

Key words: ISJ Theoretical \& Applied Science, DOI, ThomsonReuters, Scopus, Scientific journal.

Language: Russian

Citation: Shevtsov AN (2014) THE PRIORITIES OF THE DEVELOPMENT OF SCIENTIFIC JOURNAL. ISJ Theoretical \& Applied Science 12 (20): 1-3. doi: http://dx.doi.org/10.15863/TAS.2014.12.20.1

\section{ПРИОРИТЕТЫ РАЗВИТИЯ СОВРЕМЕННОГО НАУЧНОГО ЖУРНАЛА}

Аннотация: Глобализация науки неизбежно приводит к появлению, и развитию новых научных изданий способных соответствовать меняющейся обстановке, индексируемых в большом числе международных наукометрических баз, и признаваемых международными агенствами и ассочиаџиями. Статья характеризует аспекты работы международного научного журнала ISJ Theoretical \& Applied Science и приоритеты дальнейтего развития.

Ключевые слова: научный журнал, аспекты развития, международные базы.

Уважаемые авторы научного журнала ISJ Theoretical \& Applied Science!

Всвязи с ростом интереса к наукометрическим аспектам деятельности и стремления ученых к научному росту, для получения большей известности в научных кругах, и развития тесных научных связей - хочется прояснить аспекты работы и функционирования издания, а также приоритеты дальнейшего развития.

Журнал изначально позиционировался как международное издание которое бы охватило большое число стран в формате научных конференций. Периодические изменения в оформлении и требований, а также экономическая политика связана исключительно с развитием журнала и соответствия достаточно высоким требованиям, и международным контрактам заключенным с зарубежными организациями. Считаем, что данные аспекты в настоящее время, являются необходимым условием развития современного издания.

К сожалению многие другие издания не могут обеспечить для своих журналов, и сборников вхождение и индексацию даже в РИНЦ и соответственно - не представляют не только для мировой науки, но и для Российской науки - никакого интереса.

Между тем, ISJ Theoretical \& Applied Science входит, более чем, в 18 международных наукометрических баз, и имеет оценки импакт фактора за 2013-2014 года с максимальным значением Impact Factor $=\mathbf{1 . 5 0 0}$ [1].

Для многих ученых главный критерий выбора издания, для публикации статей, и главная цель - это научный рост индекса Хирша. А в Казахстане и других странах бывшего СНГ и России, публикации, можно сказать, просто списываются при подаче в отечественные устаревшие издания, не имеющие никаких связей с современной наукой. 
Мы, в свою очередь, на первый план выдвинули задачу вхождения в максимальное число наукометрических баз, и размещения там подробной библиографической информации авторов и полных текстов статей.

Это обеспечивает Вам, как авторам:

- гарантию индексации статьи во всех передовых, в научном плане, странах,

- получение научного индекса Хирша. В связи с этим убедительная просьба для всех авторов зарегистрироваться в РИНЦ и затем в системе ScienceIndex

http://elibrary.ru/ad click.asp?adid=29\&adlink=/proj ects/science index/author tutorial.asp

(для получения индекса Хирша).

Становится обидно за Казахстан видя, что почти ни один из ученых не входит в него (Российские и зарубежные ученые входят почти все... порядка $70 \%$ ) не говоря про другие научные объединения (ScienceDirect, ThomsonReuters, Scopus и многие другие...). А ведь это и приводит к научному росту ученого.

- доступность электронной версии статьи не менее 50 ближайших лет в интернете и неизменность гиперссылок на статью в PDF [2].

- лицензирование каждой статьи и автора в DOI (USA), признаваемой во всем мире (только за ноябрь 2014 г. в DOI было проиндексировано более 130 миллионов статей, а за весь 2014г. более 1,3 миллиарда статей) [3-4].

Довольно часто, преподаватели и университетская наука занята повышением внутренних университетстких рейтингов, вместо развития науки. С кафедр зачастую только одиндвое пытаются, что-то делать... писать статьи, проводить исследования... а большинство только хотят ничего не делать и получать высокие баллы по внутреннему университетскому рейтингу. Приходится в приказном порядке заставлять наших ППС заниматься "наукой". Надеемся, конечно что ситуация со временем улучшится.

Хочется предостеречь авторов от публикации в фальшивых журналах которые открываются на один день. Они пишут, что индексируются в ThomsonReuters, Scopus, РИНЦ ставя цель собрать деньги и исчезнуть. Такие журналы легко узнать по тому, что они по самым минимальным критериям не соответствуют требованиям этих организаций. На их сайте нет архива со всеми предыдущими выпусками, который просто необходим. Они также предлагают посреднические услуги по публикации статей от 300 до 1500 долларов за содействие в публикации в совершенно бесплатных журналах.

Очень часто наши авторы просят сообщить им о каком либо издательстве и охарактеризовать журнал. Большинство из которых на поверку оказывается фальсификацией и имеют только неделю назад созданный сайт, и естественно не имеющее никаких связей с наукометрическими базами и не индексируемых нигде.

Индексация в Scopus и ThomsonReuters возможна только если журнал издается более 2 лет. Расчет трехлетнего импакт фактора по этим базам возможен только за 2011-2013гг.

Теперь об актуальном для журнала ISJ Theoretical \& Applied Science и вопросам которые задают авторы:

\section{1. Каково назначение DOI?}

Лицензирование в DOI и других наукометрических базах обеспечивает авторам нашего журнала - неизменность ссылки на статью, и открытый доступ к полному тексту статьи, в течение 50 лет, даже после закрытия журнала (если журнал по каким либо причинам прекратит свое существование), а также доступность статьи из базы ThomsonReuters [2].

2. Почему меняются требования по оформлению?

Учет требований каждой наукометрической базы где индексируется журнал вносит свои изменения в оформление и меняет требования. До вхождения в DOI статьи принимались на региональных языках, на данный момент такой возможности нет. Через некоторое время вполне возможно останется только английский. К этому стремится весь научный мир - говорить на одном научном языке.

3. Каков текущий уровень журнала и особенности регистрациич?

Региональные коды ISBN необходимы только мелким изданиям которые не могут обеспечить периодичность выпуска своих сборников, не уверены в дате выпуска и вообще будет ли сама публикация сборника. Организации выдающие ISBN коды являются дочерними отделениями более глобальной компании расположенной во Франции Международного агенства CIEPS.

Для всех остальных издательств (периодические издания) - код ISSN отдельно для печатной и электронной версии дает возможность не использовать ISBN - показывая более высокий уровень как самого журнала, так и издательства. ISSN (print) - зарегистрирован в CIEPS по стране где печатается журнал. Причем индексируется в РИНЦ как зарубежное издание.

Электронная версия статьи и журнала ISSN (online) не имеет данного свойства и официально имеет статус той страны которая указана на публикации! В связи с чем страна отражена на каждой странице, в соответствии со всеми международными стандартами! 
соответствующими странами имеются договоренности на проведение очных конференций, а авторам предоставляется сертификат участника конференции.

Формат выхода журнала, был определен организаторами с трех стран США, Швеции и Казахстана (а также со временем были подключены и другие), на данный момент онлайн конференция. Мы планировали еще год назад перевести всё в очный формат, но это оказалось нецелесообразно в связи с малым количеством участников и отсеивания более $55 \%$ статей, как несоответствующих минимальным требованиям. Приоритет развития пока сдвинут на индексацию в наукометрических базах и качественное развитие журнала, а не вторичные аспекты работы: обучение авторов, встречи, выступления, известность, прибыль и др.

Хочется немного остановиться на рейтинговой системе оценивания принятой во многих вузах. Рейтинговая система в вузах приводит к необходимости определения принадлежности журнала к стране. Считаю, что одна из современных проблем идентификации журналов заключается в Глобализации науки, хотя это и неизбежно. Сейчас многие журналы индексируемые в Scopus и выходящие в электронном формате - вообще не имеют страны публикации (а сам журнал не публикуется в печатной версии). Причем на страницах страна и какие либо принадлежности к государству не указывается. Это перестает быть актуальным для мировой науки.

4. Какова последовательность индексации, рецензирования и публикации статьи?

Препринт статьи автор получает сразу после одобрения статьи редколлегией. Каждая статья проходит проверку на плагиат по Российской и зарубежной базе (USA). Индексация в DOI осуществляется 31 числа каждого месяца посредством специализированного программного обеспечения принадлежащего журналу. Индексация в ISI, РИНЦ и других базах в течение 1-2 дней (по договору это необходимо осуществлять в течение 15 дней, иначе издательство исключается).

5. Каковы дальнейшие перспективы развития журнала?

Через некоторое время будет подключена система CrossMark для отслеживания обновлений научных исследований данного автора по его тематике, а также некоторые другие сервисы.

Завершается лицензирование статей опубликованных в журнале в 2013 году в DOI, все статьи за 2014 год уже пролицензированы.

В 2015 году планируется регистрация еще в нескольких десятках наукометрических баз и международных научных организациях.

Подключено индексирование статей в базе ThomsonReuters EndNote (USA), предназначенной для работы с библиографическими списками статей. В течение месяца все опубликованные статьи будут проиндексированы в ней, а все авторы опубликованных статей получат доступ к базе.

\section{Заключение:}

Лицензирование статей в DOI и непосредственная работа с международными наукометрическими базами (USA, UAE, Russia, Japan, Turkey, Germany, India, United Kingdom, Australia и др.), а также заключенные договора с Publishers International Linking Association (USA) и другими организациями - дают нашим авторам гарантии качества издания, свободного доступа (Open Access Creative Commons Attribution License) и признания публикации во всем мире.

Приближается 24 выпуск журнала, соответственно, в ближайшей перспективе, в 2015 году, журнал будет включен в ThomsonReuters и Scopus. На данный момент журнал соответствует всем критериям данных ассоциаций. Лицензирование в DOI уже сейчас позволяет получить доступ к статьям опубликованным в ISJ Theoretical \& Applied Science и учитывать их при расчете индекса Хирша в базе ThomsonReuters.

\section{Благодарим всех за проявленный интерес к журналу! Надеемся на дальнейшее плодотворное сотрудничество!}

\section{References:}

1. (2014) ISJ Theoretical \& Applied Science. Available: (Accessed: 13.12.2014).

2. (2014) PILA_Membership_Agreement_5.21_ CEO_A_Shevtsov from Sep 12, 2014.
3. (2014) Resolution Report for prefix 10.15863 from Nov 12, 2014.

4. (2014) Resolution Report for prefix 10.15863 from Dec 10, 2014. 